\title{
Peripheral ameloblastoma: A case report
}

\author{
Shivani Bhandari ${ }^{1 *}$, Seema Sharma ${ }^{2}$, Parul A Jhamb ${ }^{3}$, Manu Gupta ${ }^{4}$ \\ ${ }^{1}$ Post Graduate Student, ${ }^{2}$ Professor and Head, ${ }^{3,4}$ Reader, Dept. of Oral and Maxillofacial Pathology and Microbiology, Santosh Dental \\ College, Ghaziabad, Uttar Pradesh, India
}

*Corresponding Author: Shivani Bhandari

Email: docshivanibhandari@gmail.com

\begin{abstract}
An ameloblastoma is benign and locally aggressive odontogenic tumor of epithelial origin. This tumor comprises about $1 \%$ of tumors and cysts arising in the jaws. Because of its slow-growing nature, there is often a delay in the diagnosis. There may be a high local recurrence rate when the tumor is not properly removed, due to remaining tumor cells. Treatment decisions for ameloblastoma are based on the individual patient situation and the best judgment of the surgeon. This is a case report of a peripheral ameloblastoma that was treated with surgical excision, but resulted in recurrence after eight months.
\end{abstract}

Keywords: Ameloblastoma, Peripheral ameloblastomas (PA).

\section{Introduction}

Mandibular swellings can be caused by many benign lesions of odontogenic or non-odontogenic origin. The most common tumor of odontogenic origin is ameloblastoma. Ameloblastoma is an aggressive benign odontogenic tumor of epithelial origin that originates from remnants of the dental lamina (cell rest of Serres) and dental organ (odontogenic epithelium). It is a painless, slow growing and locally aggressive tumour that causes expansion of the cortical bone and leads to perforation of the lingual or buccal cortical plate and infiltrates the soft tissues. This tumour is mostly found in the ramus of the mandible ${ }^{1}$ and is occasionally associated with an un-erupted third molar tooth. ${ }^{2}$ The ameloblastoma has following variants: Solid or unicystic, multicystic, extraosseous/peripheral and desmoplastic. ${ }^{3}$

\section{Case Report}

A 65-year-old male patient reported to the Department of Oral \& Maxillofacial Pathology with the chief complaint of persistence of swelling present over the left anterior buccal aspect of the gingiva with respect to (w.r.t.) 35, 36 and 37 since 8 months. The patient had no positive, associated medical and family history. Dental history of the patient comprised of tooth extraction w.r.t 37 and 38 following which the patient noticed a small proliferating growth in the region of extraction site, i.e. mandibular left posterior region in the vestibule. The swelling gradually increased in size and had no pain, bleeding or discharge. After noticing the swelling, patient visited a private dentist and surgical excision of the lesion was done. After excision, patient noticed regrowth of the tissue in the same region after a week. Patient visited Santosh dental college and hospital for the same reason.

There was no documentation of prior biopsy, histopathological examination or treatment to verify the diagnosis. Extraoral examination showed no significant change in the facial form or profile (Fig. 1). An intraoral examination revealed an ill-defined solitary swelling in the left lower posterior buccal vestibule extending anterioposteriorly from premolar region to the retromolar region.
The size of the swelling medio-laterally is $1.5 \mathrm{~cm}$ from the buccal surface of the molars and anterio-posteriorly measuring approximately $8 \mathrm{~cm}$ in length and $3 \mathrm{~cm}$ in width with overlying tissue which was pinkish red in colour (Fig. 2).

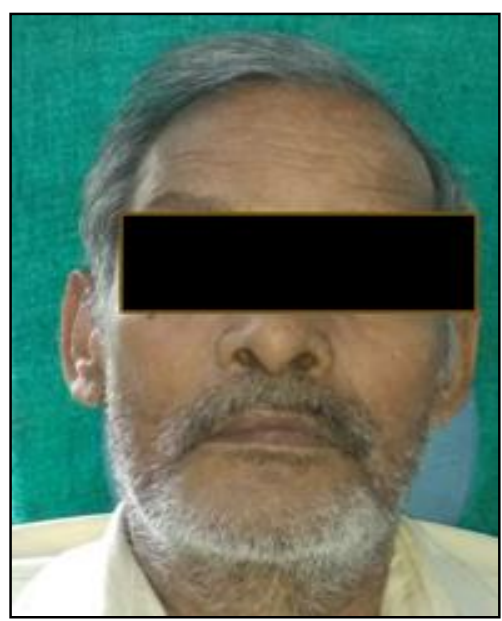

Fig. 1: Extra oral examination

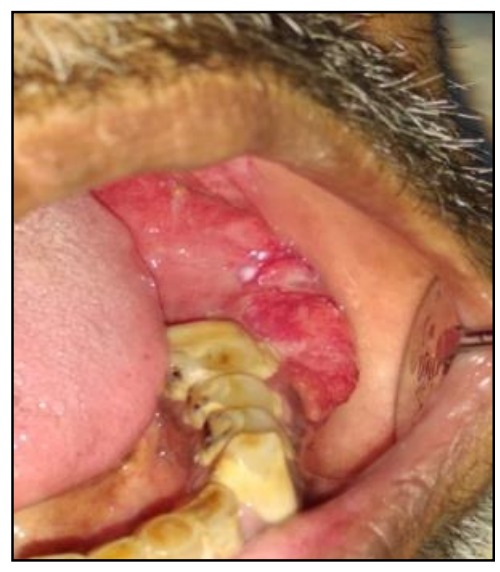

Fig. 2: Intraoral examination. 
Radiographic examination revealed no intra osseous pathology as the lesion was of soft tissue origin. Based on clinical and radiographic examination, a provisional diagnosis was made as pyogenic granuloma, and an excisional biopsy was performed under local anaesthesia after which the tissue specimen was sent for histopathological examination.

\section{Histopathological examination}

All the bits of soft tissue specimen obtained from the patient were grossed. The specimen was creamish-brown in colour, firm in consistency \& irregular in shape which measured about $8 \mathrm{~cm}$ in length and $3 \mathrm{~cm}$ in width altogether (Fig. 3 ).

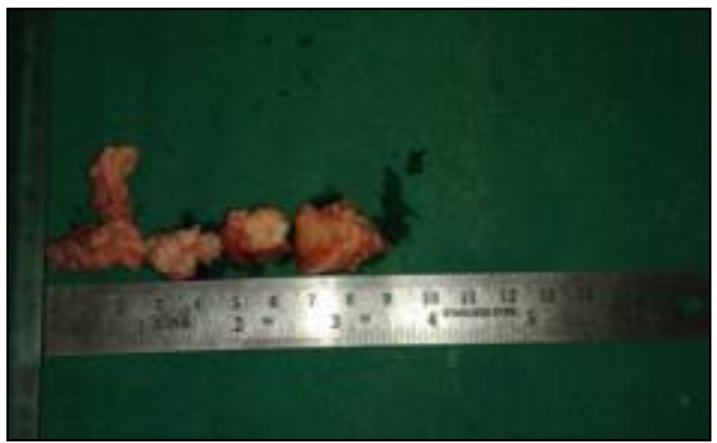

Fig. 3: Grossing

Microscopically, the section showed connective tissue stroma with epithelial follicles. The follicles were lined by peripheral tall columnar ameloblast like cells with palisaded hyperchromatic nuclei and centrally placed stellate reticulum like cells. Microcyst formation and squamous metaplasia associated with keratin formation was seen in the central portion of epithelial follicle. The surrounding connective tissue stroma was scanty and moderately fibrous. Few capillaries and RBSs were also appreciated. These findings were suggestive of acanthomatous ameloblastoma (Fig. 4 6)

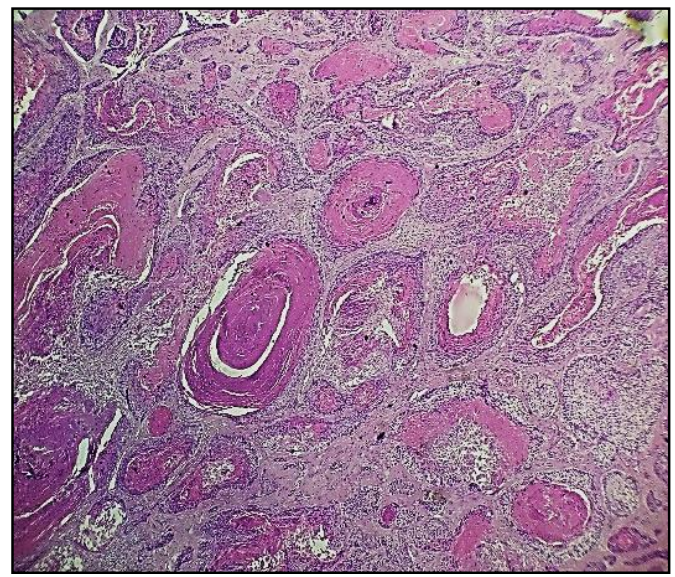

Fig. 4: 4X: The $\mathrm{H}$ \& $\mathrm{E}$ stained tissue section shows connective tissue stroma with epithelial follicles.

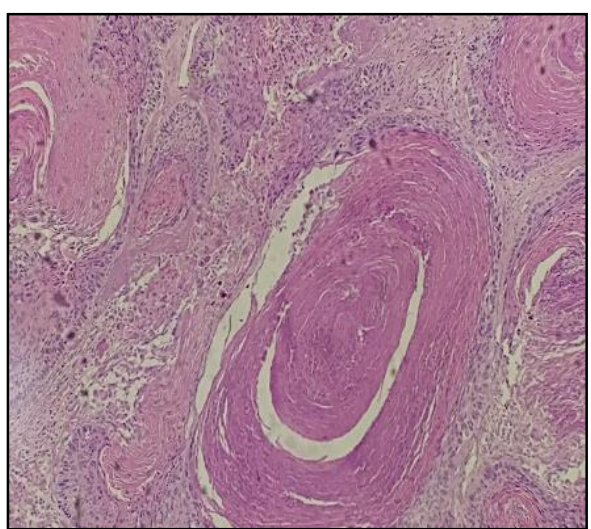

Fig. 5: 10X - Squamous metaplasia associated with keratin formation is seen in the central portion of epithelial

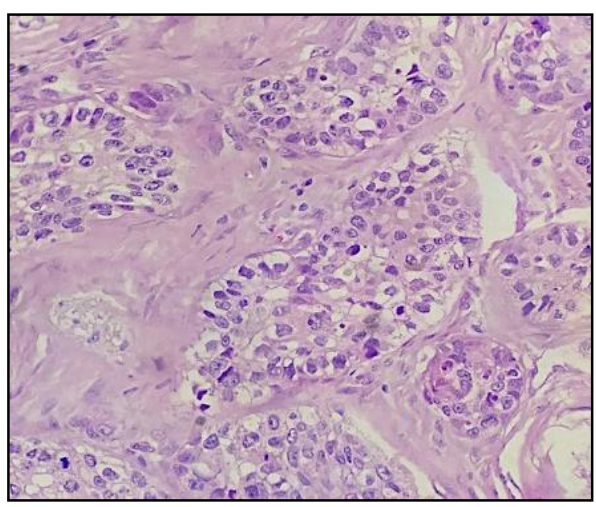

Fig. 6: The follicles are lined by peripheral tall columnar ameloblast like cells with palisaded hyperchromatic nuclei and centrally placed stellate reticulum like cells. The connective tissue exhibits spindle shaped fibroblasts.

\section{Discussions}

Ameloblastoma is the second most common odontogenic tumor. In India, it is reported as the most common odontogenic tumor. Ameloblastoma appears in the age group of 20-50 years with equal frequency having no gender predominance. ${ }^{4,5}$

Peripheral ameloblastomas (PA) are exceedingly rare tumors, constituting about $1 \%$ of all ameloblastomas. These tumors are typically found in the retromolar region of the mandible. Other less common regions include the maxillary tuberosity, buccal mucosa or the floor of the mouth. The majority of ameloblastomas are derived from the odontogenic apparatus i.e. odontogenic epithelium, enamel organ and its derivatives or less commonly from the lining of a dentigerous cyst. ${ }^{6}$

\section{Conclusion}

Ameloblastoma is considered to be a benign, but locally invasive odontogenic tumor with a high rate of recurrence. As it is commonly seen, most of the gingival swellings or overgrowths are at times misdiagnosed clinically as pyogenic granuloma and are surgically excised as it is the most recommended treatment of choice. During first clinical examination this case was also diagnosed as pyogenic 
granuloma but after thorough histological examination, the lesion was diagnosed as peripheral ameloblastoma. Hence, the histological examination is important in diagnosing the lesion so that the adequate treatment is provided to the patient without any recurrence of the lesion as the recurrence rate of ameloblastoma is much higher than pyogenic granuloma.

\section{Source of funding}

None.

\section{Conflict of interest}

None.

\section{References}

1. Ghandhi D, Ayoub AF, Pogrel MA, MacDonald G, Brocklebank LM, Moos KF. Ameloblastoma: A surgeon's dilemma. J Oral Maxillofac Surg 2006;64(7):1010-14.
2. Robinson L, Martinez MG. Unicystic ameloblastoma: A prognostically distict entity. Cancer 1977;40(5):2278-85.

3. Barnes L, Everson JW, Reichart P, Sindransky D. WHO classification of tumours series. In Pathology and Genetics of Head and Neck Tumous. IARC Press; 2005:2(1).

4. Wood NK, Goaz PW. Differential Diagnosis of Oral and Maxillofacial Lesions $5^{\text {th }}$ ed. Missouri: Mosby Elsevier; 2011:337-40.

5. White SC, Pharoah MJ. Oral Radiology: Principles and Interpretation. 5th ed. New Delhi: Mosby Elsevier; 2005:41922.

6. Worth HM. Principles and Practice of Oral Radiologic Interpretation. Chicago: Year Book Medical Publishers Inc; 1975:476-94.

7. Weissman JL, Snyderman CH, Yousem SA, Curtin HD. Ameloblastoma of the maxilla: CT 4and MR appearance. Am J Neurorad 1993;14(1):223-6. 